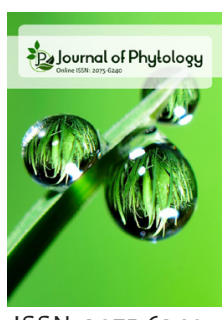

ISSN: $2075-6240$

\title{
Diversity analysis and structural modeling of some traits in wheat genotypes
}

\author{
Maysoun M. Saleh*, Rajaa Kenaan², Zaeda Alsayd Suliman³, Walid A. Ali, \\ Yaman Jabbour ${ }^{5}$ \\ ${ }^{1}$ Genetic Resources Department, General Commission for Scientific Agricultural Research, Damascus, Syria, \\ ${ }^{2}$ Al-Swaida Agricultural Centre, General Commission for Scientific Agricultural Research, Al-Swaida, Syria, ${ }^{3} \mathrm{Homs}$ \\ Agricultural Centre, General Commission for Scientific Agricultural Research, Homs, Syria, ${ }^{4}$ Tartous Agricultural \\ Centre, General Commission for Scientific Agricultural Research, Tartous, Syria, ${ }^{5}$ Aleppo Agricultural Centre, \\ General Commission for Scientific Agricultural Research, Aleppo, Syria
}

\begin{abstract}
This investigation was carried out during 2018/2019 season in three locations (Homs, Al-Swaida and Tartous) belongs to the General Commission for Scientific Agricultural Research in Syria, using 17 Italian, Syrian and Ethiopian wheat genotypes to estimate the potential diversity by principle component and cluster analysis, and to study the structural modeling between grain yield and other traits to define best traits as predictors and selection indexes of grain yield, and to determine the superior genotypes in grain yield. Results indicated a remarkable variation of $74 \%$ due only to the first four principle components with Eigen value more than 1. PC Biplot showed that Tartous was the best location, and the genotype SD09 was superior in grain yield per plant followed by SH5 and IP39. Structural modeling results revealed that the total and fertile tillers number per plant were the best predictors for grain yield per plant, while fertile tillers per plant with grains weight per spike could be used as selection indexes of wheat grain yield because they had positive strong direct effect on grain yield per plant. Cluster analysis results confirmed the need to assess more various genotypes from different origins.
\end{abstract}

Email: mzainsamasaleh@gmail.com KEYWORDS: Wheat, diversity, structural modeling, PCA, biplot, cluster

*Corresponding Author:

Maysoun M. Saleh

Revised: December 23, 2020

Accepted: December 26, 2020

Published: December 30, 2020

\section{INTRODUCTION}

Wheat is the most important grain crop in the world which provide people with almost $50 \%$ of the required calories [1]. Breeding programs aim to increase the selection efficiency by assessing more genetic variations among wheat genotypes [2], this can be studied through different methods of multivariate analysis such as principle component and cluster analysis. Principle component analysis is used to reduce the large number of traits to a limited number which represents the majority of the existent variation [3]. Al-Otayk [4] applied principle component analysis to study the variation in wheat germplasm, their results showed remarkable variation among them. Categorize germplasm in many groups depending on their variation is applied by Cluster analysis [5]. Cluster analysis was applied by Devesh et al. [1] depending on the agronomic traits of various wheat trait. Poudel et al. [6] estimated the diversity between wheat genotypes, their results showed that wheat genotypes were clustered in various main and sub main clusters. Sahu et al. [7] declared that correlation is used to just to illustrate relation between traits, but not for prediction of any trait, whereas path analysis considers as an efficient method for confirming the correlation depending on the effects and reasons of these effects and to eliminate any false effect. Abd El-Mohsen [8] mentioned that prediction of grain yield via other traits can be applied by regression analysis. The objectives of this investigation were to: (i) evaluate the magnitude of potential diversity between exotic and local wheat genotypes by using principal component analysis and cluster analysis, (ii) study the nature of structural modeling between grain yield and other traits via Regression and path analysis, (iii) define the superior genotypes regarding grain yield in various locations to be used in breeding programs.

\section{MATERIAL AND METHODS}

\section{Plant Materials}

Seventeen genetic resources of primitive wheat originated from different countries (Italy, Ethiopia and Syria) were used 
in this study (Table 1). They were kindly provided by the International Centre for Agricultural Research in the Dry Areas (ICARDA), and by the genetic resources department in the General Commission for Scientific Agricultural Research (GCSAR), Syria.

\section{Field Experiments}

The investigation was carried out at three research centers (Homs, Al-Swaida and Tartous) in the General Commission for Scientific Agricultural Research (GCSAR), Syria during the season 2018/2019. The experiment was arranged in a randomized complete block design (RCBD), with three replicates. Each replicate consisted of four rows, each row of lmeter long, with $20 \mathrm{~cm}$ between rows and $5 \mathrm{~cm}$ between plants, depth of planting was $3-5 \mathrm{~cm}$. Recommended cultural practices like irrigation and pesticide control were applied according to Agricultural ministry guides. Days to flowering, days to heading, plant height $(\mathrm{cm})$, awn length $(\mathrm{cm})$, total tillers number per plant, fertile tillers number per plant, spike length $(\mathrm{cm})$, spike peduncle length $(\mathrm{cm})$, grain number per spike, granis weight per spike, 1000-grain weight(g) and grain yield per plant $(\mathrm{g})$ were all measured on ten randomly selected plants (Table 2).

\section{Statistical Analysis}

Summary statistics were analyzed by SPSS.12 software. Principal component analyses to assess level of variance in traits between genotypes was conducted by Minitap.12 software. Cluster analysis was also analyzed via Minitap.12 software depending on single linkage method with Euclidean distance measure. Correlation and simple linear regression SLR between grain yield per plant as the dependent variable and each of the studied traits as independent variables and Biplot were all analyzed via Genstat.12 software. Path coefficients analysis to identify the direct and indirect effects of studied traits on grain yield was done according to Singh and Chudhary [9] using Genstat.12 software, the strength of direct and indirect effects value was scaled according to [10] as follows: More than 1: very strong,

Table 1: List of wheat genotypes used in this study

\begin{tabular}{llll}
\hline No & Genotype & Origin & Species \\
\hline 1 & IP39 & Italy & Triticum polonicum \\
2 & IP40 & Italy & Triticum polonicum \\
3 & IP45 & Italy & Triticum polonicum \\
4 & IP46 & Italy & Triticum polonicum \\
5 & IP47 & Italy & Triticum polonicum \\
6 & IP49 & Italy & Triticum polonicum \\
7 & IP50 & Italy & Triticum polonicum \\
8 & IP52 & Italy & Triticum polonicum \\
9 & IC80 & Italy & Triticum carthlicum \\
10 & IC81 & Italy & Triticum carthlicum \\
11 & IC83 & Italy & Triticum carthlicum \\
12 & IC89 & Italy & Triticum carthlicum \\
13 & ED04 & Ethiopia & Triticum dicoccum \\
14 & SD09 & Syria & Triticum dicoccum \\
15 & SD11 & Syria & Triticum dicoccum \\
16 & SH3 & Syria & Triticum durum \\
17 & SH5 & Syria & Triticum durum
\end{tabular}

(0.3 - 0.9): strong, (0.2 - 0.29): medium, $(0.1-0.19)$ weak, less than 0.1: neglected.

\section{RESULTS AND DISCUSSION}

Summary statistics for studied traits revealed that the mean of (days to heading and days to flowering) was $(132.95,136.03)$ day respectively, with a range of $(56.00,62.00)$ day respectively. Mean of (plant height, awn length, spike length and spike peduncle length) was $(124.33,10.25,11.23,40.18) \mathrm{cm}$ respectively with a range of $(156.20,14.30,16.70,44.63) \mathrm{cm}$ respectively. The range of total and fertile tillers number per plant was $(52.60,34.30)$ respectively, with a mean of $(16.73,11.86)$ tiller respectively. The mean and range of grains number per spike were (11.23 and 84.60) grain respectively.

Results also indicated that the mean of (granis weight per spike, 1000-grain weight and grain yield per plant) was (1.50, 35.37 and 13.55$) \mathrm{g}$ respectively with a range of $(4.70,73.70$, $50.71) \mathrm{g}$ respectively. Grain yield per plant was the main source of the explored variations between wheat genotypes since its coefficient of variation reached $61.9 \%$, followed by grain weight per spike $46 \%$ (Table 3). Other traits such as fertile tillers number per plant and grains number per spike also were sources of remarkable variation $(39.7,35.8)$ respectively.

\section{Principle Component Analysis}

Twelve principal components were obtained for the studied traits, but only the first four principal components (PC1, PC2, PC3 and PC4) present the variability between wheat genotypes relating to studied traits as they revealed Eigen value larger than $1.0(3.85,2.49,1.51$ and 1.10$)$ respectively (Figure 1), while other components were neglected as they resulted an Eigen value less than one. The maximum variability was $74 \%$ divided to $(32.1,20.7,12.6$ and 9.2) \% revealed by the first four principle components (PC1, PC2, PC3 and PC4) respectively (Table 4). The first principal component $\mathrm{PCl}$ consisted of plant height and spike peduncle length (-0.347 and -0.386) respectively. The second principal component PC2 contained four traits: days to flowering and days to heading, fertile tillers number per plant and grain yield per plant $(0.476,0.527,-0.349,-0.373)$ respectively. Also the third principal component PC3 enclosed four traits: awn length, total tillers number per plant, grains weight per spike and 1000-grain weight $(0.396,-0.506,0.370$ and $0.320)$ respectively. Spike length and grains number per spike

Table 2: List of Traits abbreviations used in this study

\begin{tabular}{llll}
\hline Trait & abbreviation & Trait & abbreviation \\
\hline FD & Days to flowering & GWS & Grains weight per spike \\
HD & Days to heading & TGW & 1000- grain weight \\
PH & Plant height & GYP & Grain yield per plant \\
AL & Awn length & Tar & Tartous location \\
TT & Total tillers number & SW & Al-Swaida location \\
FT & Fertile tillers number & Ho & Homs location \\
SL & Spike length & CV & Coefficient of Variation \\
SPL & Spike peduncle length & SD & Standard Deviation \\
GNS & Grains number per spike & & \\
\hline
\end{tabular}


Table 3 : Means and content of variations of 17 studied genotypes

\begin{tabular}{lccccc}
\hline Trait & Mean & Sum & Range & CV\% & SD \\
\hline Hd & 132.95 & 20342.00 & 56.00 & 1.8 & 11.02 \\
Fd & 136.03 & 20813.00 & 62.00 & 3.4 & 11.09 \\
PH & 124.33 & 19021.97 & 156.20 & 14.2 & 33.08 \\
AL & 10.25 & 1568.70 & 14.30 & 17.7 & 3.08 \\
TT & 16.73 & 2559.00 & 52.60 & 33.1 & 8.74 \\
FT & 11.86 & 1813.81 & 34.30 & 39.7 & 6.41 \\
SL & 11.23 & 1717.85 & 16.70 & 19.5 & 3.15 \\
SPL & 40.18 & 6147.84 & 44.63 & 17.0 & 10.60 \\
GNS & 11.23 & 1717.85 & 84.60 & 35.8 & 3.15 \\
GWS & 1.50 & 230.24 & 4.70 & 46 & 0.89 \\
TGW & 35.37 & 5411.45 & 73.70 & 17.6 & 12.07 \\
GYP & 13.55 & 2073.65 & 50.71 & 61.9 & 12.02 \\
\hline
\end{tabular}

Table 4: Eigen value, proportion and cumulative variation of analyzed components

\begin{tabular}{lccc}
\hline $\begin{array}{l}\text { Principal } \\
\text { components }\end{array}$ & $\begin{array}{c}\text { Eigen } \\
\text { value }\end{array}$ & $\begin{array}{c}\text { Proportion of } \\
\text { variation\% }\end{array}$ & $\begin{array}{c}\text { Cumulative } \\
\text { variation\% }\end{array}$ \\
\hline PC1 & 3.85 & 0.321 & 0.321 \\
PC2 & 2.49 & 0.207 & 0.528 \\
PC3 & 1.51 & 0.126 & 0.654 \\
PC4 & 1.10 & 0.092 & 0.746 \\
PC5 & 0.91 & 0.075 & 0.822 \\
PC6 & 0.65 & 0.054 & 0.875 \\
PC7 & 0.55 & 0.045 & 0.921 \\
PC8 & 0.31 & 0.025 & 0.946 \\
PC9 & 0.27 & 0.023 & 0.969 \\
PC10 & 0.17 & 0.014 & 0.983 \\
PC11 & 0.20 & 0.010 & 0.993 \\
PC12 & 0.09 & 0.007 & 1.000 \\
\hline
\end{tabular}

were related to the fourth principle component PC4 (-0.750, 0.408 ) respectively (Table 5). Loading plot of the studied traits relating to the first two principle components indicated that all traits were negatively connected to $\mathrm{PCl}$ (except days to heading), while five traits: Grains weight per spike, awn length, total tillers per plant, fertile tillers per plant and grain yield per plant were negatively connected to PC2 (Figure 2). Principle components Biplot distribution of genotypes and locations for the final grain yield indicated that Tartous was the best location followed by Homs, and the genotype SD09 was superior in grain yield per plant followed by SH5 and IP39 comparing to all other genotypes (Figure 3).

\section{Correlation Analysis}

Results showed significant positive correlation between days to flowering and days to heading $\left(0.749^{* * *}\right)$, plant height $\left(0.581^{* * *}\right)$, total tillers number per plant $\left(0.173^{*}\right)$, spike peduncle length $\left(0.472^{* *}\right)$, grains number per spike $\left(0.173^{*}\right)$, grain weight per spike $\left(0.195^{*}\right)$ and 1000 -grain weight $\left(0.359^{* *}\right)$. Correlation was positive and significant between days to heading and plant height $\left(0.244^{* * *}\right)$, while negative and significant with each of awn length $\left(-0.251^{* *}\right)$, fertile tillers number per plant $\left(-0.275^{* * *}\right)$ and grain yield per plant $\left(-0.456^{* * *}\right)$. Plant height had a positive significant correlation with awn length $\left(0.314^{* * *}\right)$, total tillers number per plant $\left(0.269^{* *}\right)$, fertile tillers number per plant $\left(0.185^{*}\right)$, spike length $(0.379 * *)$, spike peduncle length $\left(0.630^{* *}\right)$, grains number per spike $\left(0.287^{* *}\right)$, grain weight

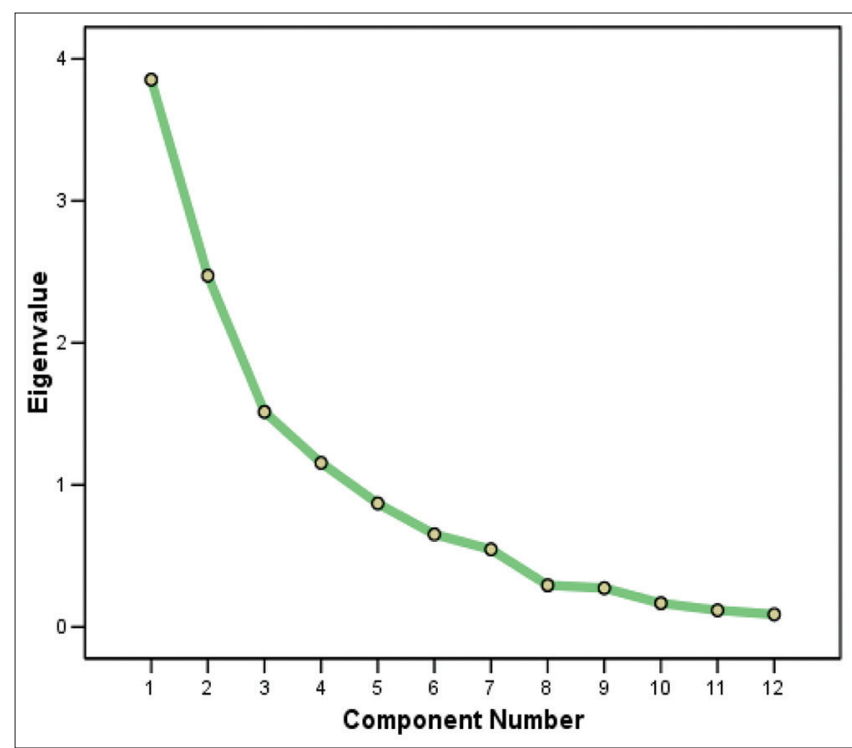

Figure 1: Scree plot showing eigen value variation

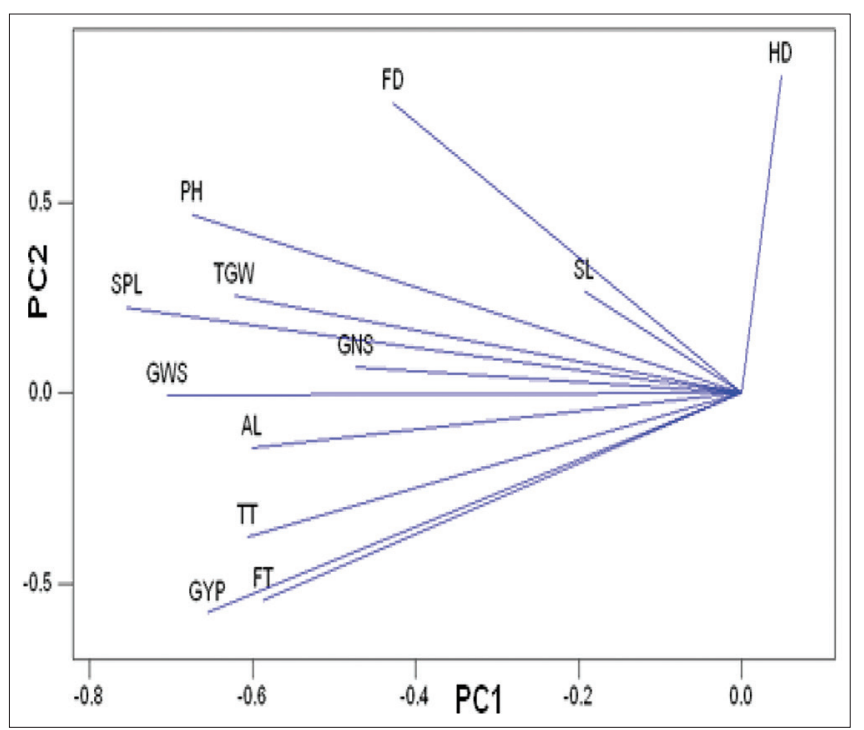

Figure 2: Loading plot of studied traits in the first two Components

per spike $\left(0.320^{* * *}\right)$ and 1000 -grain weight $\left(0.395^{* * *}\right)$. Positive significant correlation was found between total tillers number per plant and fertile tillers number per plant $\left(0.859^{* * *}\right)$, spike peduncle length $\left(0.347^{* *}\right)$, grains number per spike $(0.168 *)$ and grain yield per plant $\left(0.571^{* * *}\right)$. Also fertile tillers number per plant had a positive significant correlation with spike peduncle length $\left(0.279^{* *}\right)$, grains weight per spike $(0.170 *)$ and grain yield per plant $\left(0.649^{* *}\right)$. Spike length correlated significantly and positively with spike peduncle length $(0.174 *)$. Results also indicated significant positive correlation between spike peduncle length and grains number per spike, grains weight per spike, 1000 -grain weight and grain yield per plant $\left(0.229^{* * *}\right.$, $\left.0.438^{* * *}, 0.472^{* * *}, 0.350^{* * *}\right)$ respectively. Grains number per spike exhibited a positive and significant correlation with each of grain weight per spike and grain yield per plant $\left(0.476^{* * *}\right.$, $\left.0.173^{*}\right)$ respectively, and also between grains weight per spike and each of 1000 -grain weight and grain yield per plant $\left(0.531^{\text {*** }}\right.$, 
Table 5: The first four principle components for the studied traits

\begin{tabular}{lllll}
\hline Trait & PC1 & PC2 & PC3 & PC4 \\
\hline FD & -0.222 & 0.476 & -0.278 & 0.161 \\
HD & 0.019 & 0.527 & -0.249 & 0.280 \\
PH & -0.347 & 0.291 & -0.099 & -0.246 \\
AL & -0.305 & -0.092 & 0.396 & -0.150 \\
TT & -0.307 & -0.246 & -0.506 & 0.033 \\
FT & -0.297 & -0.349 & -0.404 & -0.006 \\
SL & -0.104 & 0.186 & -0.000 & -0.750 \\
SPL & -0.386 & 0.134 & -0.052 & -0.104 \\
GNS & -0.240 & 0.068 & 0.176 & 0.408 \\
GWS & -0.357 & -0.009 & 0.370 & 0.255 \\
TGW & -0.318 & 0.154 & 0.320 & -0.017 \\
GYP & -0.329 & -0.373 & -0.032 & 0.081 \\
\hline
\end{tabular}

$\left.0.557^{* *}\right)$ respectively, and finally between 1000-grain weight and grain yield per plant $\left(0.244^{* *}\right)$ (Table 6). All correlations between studied traits were plotted (Figure 4).

\section{Regression Analysis}

Results of simple linear regression SLR to predict grain yield per plant as a dependent trait by each of other studied traits as independent traits reveled that only six traits can be used as predictors of grain yield per plant (days to heading, awn length, total tillers per plant, fertile tillers per plant, spike peduncle length and grains weight per spike) as they had a significant regression with grain yield per plant (Table 7). The coefficient of determination $\mathrm{R}^{2}$ between grain yield and days to heading was 0.208 which means that the late heading genotypes will have a reduction in grain yield in rate of $20.8 \%$ because of the negative correlation between days to heading and grain yield per plant. The coefficient of determination $\mathrm{R}^{2}$ between grain yield and other traits like awn length, total tillers number per plant, fertile tillers number per plant, spike peduncle length and grain weight per plant were $(0.096$, $0.326,0.421,0.122$ and 0.310 ) respectively, indicated that each of these traits can predict separately the variation in grain yield per plant at in a rate of $(9.6,32.6,42.1,1.2$ and $3.10) \%$ respectively (Figure 5). Regression equation is listed in Table. 8.

\section{Path Analysis}

Results of path analysis showed that the direct effects on grain yield per plant for fertile tillers number per plant and grains weight per spike were strong and positive (0.33807 and 0.53401 ) respectively, while strong but negative for days to heading (-0.44066), positive and medium for days to flowering (0.23038), weak and negative for plant height and grains number per spike $(-0.11706$ and -0.11170$)$ respectively, while weak and positive for total tillers number per spike (0.17852). The direct effect of awn length, spike length, spike peduncle length and 1000 - grain weight was neglected $(-0.05714,-0.02154,0.00307$ and -0.03707$)$.

Results also revealed that the indirect effect of days to flowering via days to heading was strong and negative (-0.33017), while positive but weak via grains weight per spike $(0.10403)$, other

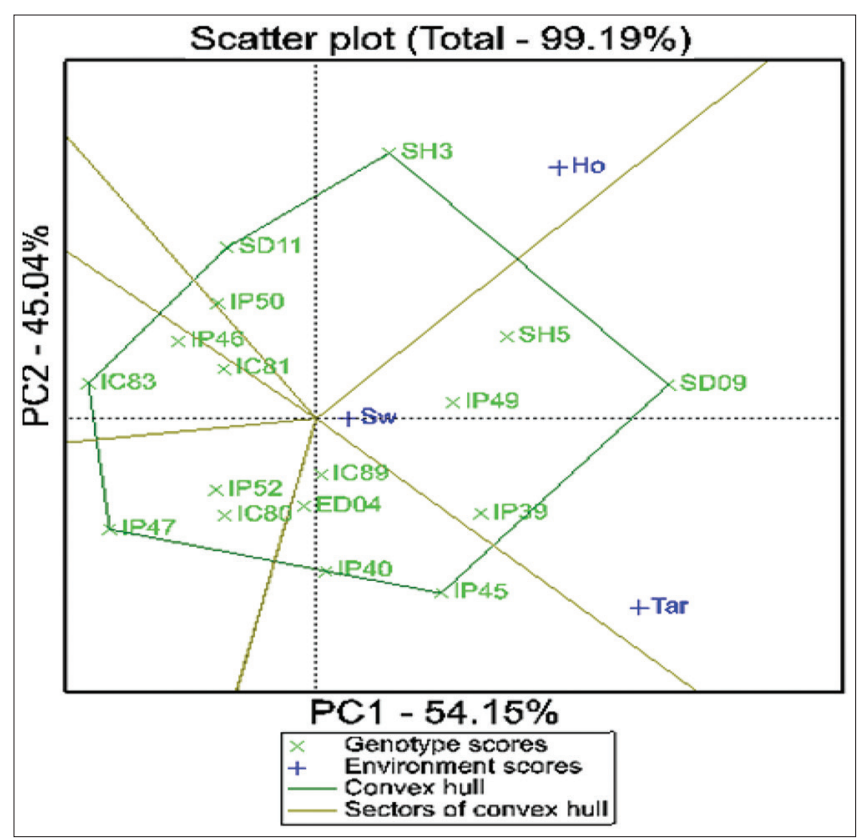

Figure 3: Principle Component Biplot of Genotypes and locations for grain yield trait

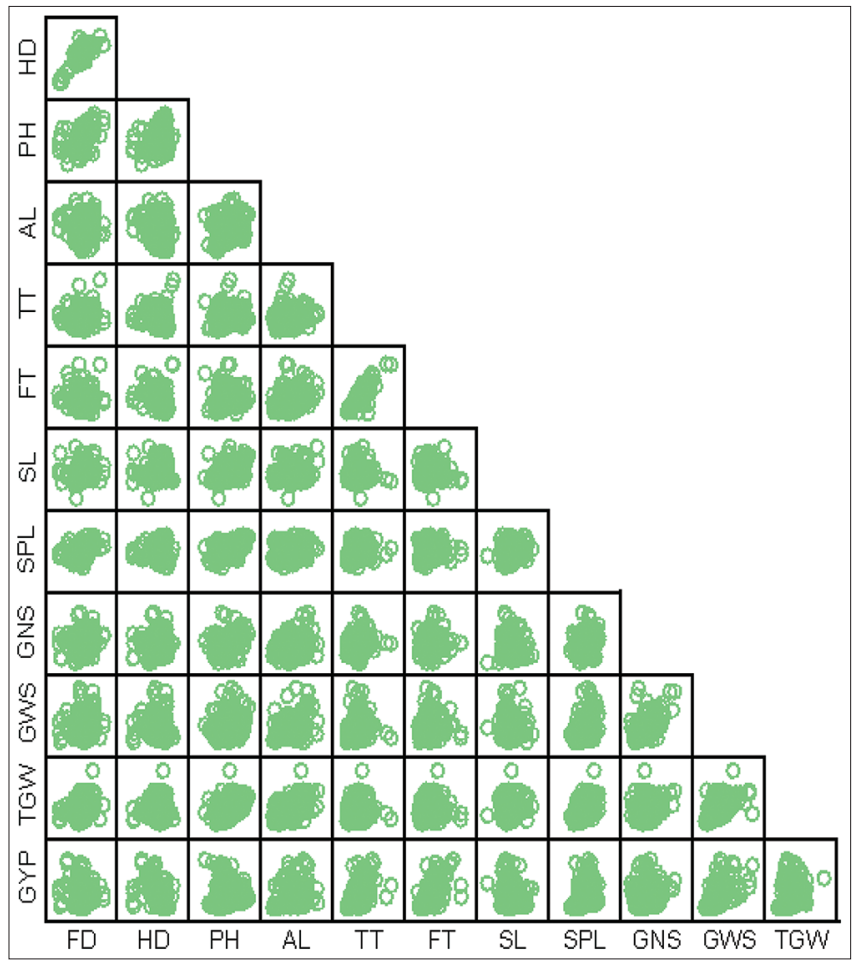

Figure 4: Loading plots of correlations between studied traits

indirect effects were neglected. The indirect effects of days to heading via other traits were all neglected except its weak and positive indirect effect via days to flowering (0.17262). Plant height had weak and positive indirect effects via days to flowering and grains weight per spike $(0.13375,0.17091)$ respectively, while weak but negative via days to heading $(-0.10734)$, and neglected indirect effects via other traits. The indirect effect of awn length was positive medium via grains 
Table 6: Correlation matrix between studied traits

\begin{tabular}{|c|c|c|c|c|c|c|c|c|c|c|c|c|}
\hline Trait & FD & HD & $\mathrm{PH}$ & $\mathrm{AL}$ & TT & FT & SL & SPL & GNS & GWS & TGW & GYP \\
\hline FD & 1 & & & & & & & & & & & \\
\hline HD & $0.749 * *$ & 1 & & & & & & & & & & \\
\hline $\mathrm{PH}$ & $0.581 * *$ & $0.244 * *$ & 1 & & & & & & & & & \\
\hline$A L$ & -0.020 & $-0.251 * *$ & $0.314 * *$ & 1 & & & & & & & & \\
\hline TT & $0.173 *$ & -0.130 & $0.269 * *$ & $0.166 *$ & 1 & & & & & & & \\
\hline FT & -0.005 & $-0.275^{* *}$ & $0.185^{*}$ & $0.267 * *$ & $0.859 * *$ & 1 & & & & & & \\
\hline SL & 0.158 & 0.073 & $0.379 * *$ & 0.183 & 0.001 & -0.017 & 1 & & & & & \\
\hline SPL & $0.472 * *$ & 0.033 & $0.630 * *$ & $0.306 * *$ & $0.347 * *$ & $0.279 * *$ & $0.174 *$ & 1 & & & & \\
\hline GNS & $0.173 *$ & 0.118 & $0.287 * *$ & $0.335 * *$ & $0.168^{*}$ & 0.138 & 0.013 & $0.229 * *$ & 1 & & & \\
\hline GWS & $0.195^{*}$ & -0.075 & $0.320 * *$ & $0.441 * *$ & 0.126 & $0.170 *$ & 0.035 & $0.438 * *$ & $0.476 * *$ & 1 & & \\
\hline TGW & $0.359 * *$ & 0.069 & $0.395 * *$ & $0.449 * *$ & 0.084 & 0.061 & 0.096 & $0.472 * *$ & 0.138 & $0.531 * *$ & 1 & \\
\hline GYP & -0.068 & $-0.456 * *$ & 0.120 & $0.309 * *$ & $0.571 * *$ & $0.649 * *$ & -0.040 & $0.350 * *$ & $0.173 *$ & $0.557 * *$ & $0.244 * *$ & 1 \\
\hline
\end{tabular}

**Correlation is significant at the 0.01 level. * Correlation is significant at the 0.05 level

Table 7: Summary of S.L.R. between grain yield and each of other studied traits

\begin{tabular}{|c|c|c|c|c|c|}
\hline Trait & Source & d. f. & M.S & $\mathrm{R}$ & $\mathrm{R}^{2}$ \\
\hline \multirow[t]{3}{*}{ FD } & Regression & 1 & $102.2^{\mathrm{NS}}$ & -0.068 & 0.005 \\
\hline & Residual & 151 & 144.7 & & \\
\hline & Total & 152 & 144.4 & & \\
\hline \multirow[t]{3}{*}{ HD } & Regression & 1 & $4562.6^{S}$ & -0.456 & 0.208 \\
\hline & Residual & 151 & 115.2 & & \\
\hline & Total & 152 & 144.4 & & \\
\hline \multirow[t]{3}{*}{$\mathrm{PH}$} & Regression & 1 & $316.2^{\mathrm{NS}}$ & 0.120 & 0.014 \\
\hline & Residual & 151 & 143.3 & & \\
\hline & Total & 152 & 144.4 & & \\
\hline \multirow[t]{3}{*}{$A L$} & Regression & 1 & $2102.1^{\mathrm{S}}$ & 0.309 & 0.096 \\
\hline & Residual & 151 & 131.5 & & \\
\hline & Total & 152 & 144.4 & & \\
\hline \multirow[t]{3}{*}{ TT } & Regression & 1 & $7166.75^{s}$ & 0.571 & 0.326 \\
\hline & Residual & 151 & 97.93 & & \\
\hline & Total & 152 & 144.4 & & \\
\hline \multirow[t]{3}{*}{ FT } & Regression & 1 & $9248.28^{S}$ & 0.649 & 0.421 \\
\hline & Residual & 151 & 84.14 & & \\
\hline & Total & 152 & 144.4 & & \\
\hline \multirow[t]{3}{*}{ SL } & Regression & 1 & $80.2^{\mathrm{NS}}$ & 0.040 & 0.002 \\
\hline & Residual & 151 & 144.9 & & \\
\hline & Total & 152 & 144.4 & & \\
\hline \multirow[t]{3}{*}{ SPL } & Regression & 1 & $2688.3^{S}$ & 0.350 & 0.122 \\
\hline & Residual & 151 & 127.6 & & \\
\hline & Total & 152 & 144.4 & & \\
\hline \multirow[t]{3}{*}{ GNS } & Regression & 1 & $490.6^{\mathrm{NS}}$ & 0.173 & 0.030 \\
\hline & Residual & 151 & 142.1 & & \\
\hline & Total & 152 & 144.4 & & \\
\hline \multirow[t]{3}{*}{ GWS } & Regression & 1 & $6814.6^{s}$ & 0.557 & 0.310 \\
\hline & Residual & 151 & 100.3 & & \\
\hline & Total & 152 & 144.4 & & \\
\hline \multirow[t]{3}{*}{ TGW } & Regression & 1 & $1301.9^{\text {NS }}$ & 0.244 & 0.059 \\
\hline & Residual & 151 & 136.8 & & \\
\hline & Total & 152 & 144.4 & & \\
\hline
\end{tabular}

${ }^{\mathrm{s}}$ Regression is significant

Table 8: Regression equations between grain yield and predictors traits

\begin{tabular}{ll}
\hline No & Regression Equation \\
\hline 1 & GYP $=79.9-0.4972 \mathrm{HD}$ \\
2 & GYP $=1.16+1.209 \mathrm{AL}$ \\
3 & GYP $=0.42+0.7853 \mathrm{TT}$ \\
4 & GYP $=-0.871 .217 \mathrm{FT}$ \\
5 & GYP $=-2.38+0.3966 \mathrm{SPL}$ \\
6 & GYP $=2.19+7.552 \mathrm{GWS}$ \\
\hline
\end{tabular}

weight per spike (0.23531), and positive weak via days to heading (0.11052), whereas neglected via other traits. Total tillers had only a positive medium indirect effect via fertile tillers per plant (0.29040), while other indirect effects were all neglected. The indirect effects of fertile tillers per plant were positive but weak via days to heading and total tillers per plant $(0.12139,0.15335)$ respectively, and all other indirect effects were neglected. Spike length had neglected indirect effects on grain yield per plant via all traits. Spike peduncle length had a positive and weak indirect effect via days to flowering $(0.10873)$ and positive and medium via grains weight per spike $(0.23409)$, other indirect effects were all neglected. All indirect effects of grains number per spike were neglected except via grains weight per spike which was medium and positive (0.25396). All indirect effects of grains weight per spike on plant grain yield via other traits were neglected. The same result for 1000-grain weight which all its indirect effects via other traits were neglected except its positive and weak indirect effect via total tillers number per spike (0.01498) and its positive and medium indirect effect via grains weight per spike (0.28364) (Table 9).

\section{Cluster Analysis}

Results of cluster analysis depending on studied field traits revealed that the similarity coefficient ranged from $43.50 \%$ to $100 \%$, and three main groups of genotypes were clustered together, each of contained sub clusters. The first main group included nine genotypes, which seven originated from Italy (IC80, IC81, IC83, IC89, IP46, IP47, IP49) and one originated from Ethiopia (ED04) and another one originated from Syria (SDl1). The second main group contained five genotypes originated all from Italy (IP39, IP50, IP40, IP45, IP52). The third main group consisted of three Syrian originated genotypes (SD09, SH3 and SH5) (Figure. 6).

\section{DISCUSSION}

According to our results, the coefficient of variation for grain yield was the highest in representing variation between wheat genotypes, this could be explained due the complex nature of yield trait which affected by most of the quantitative traits. Our results agree with the findings of Grzesiak et al. [11] who found that the coefficient of variation for wheat grain yield was 


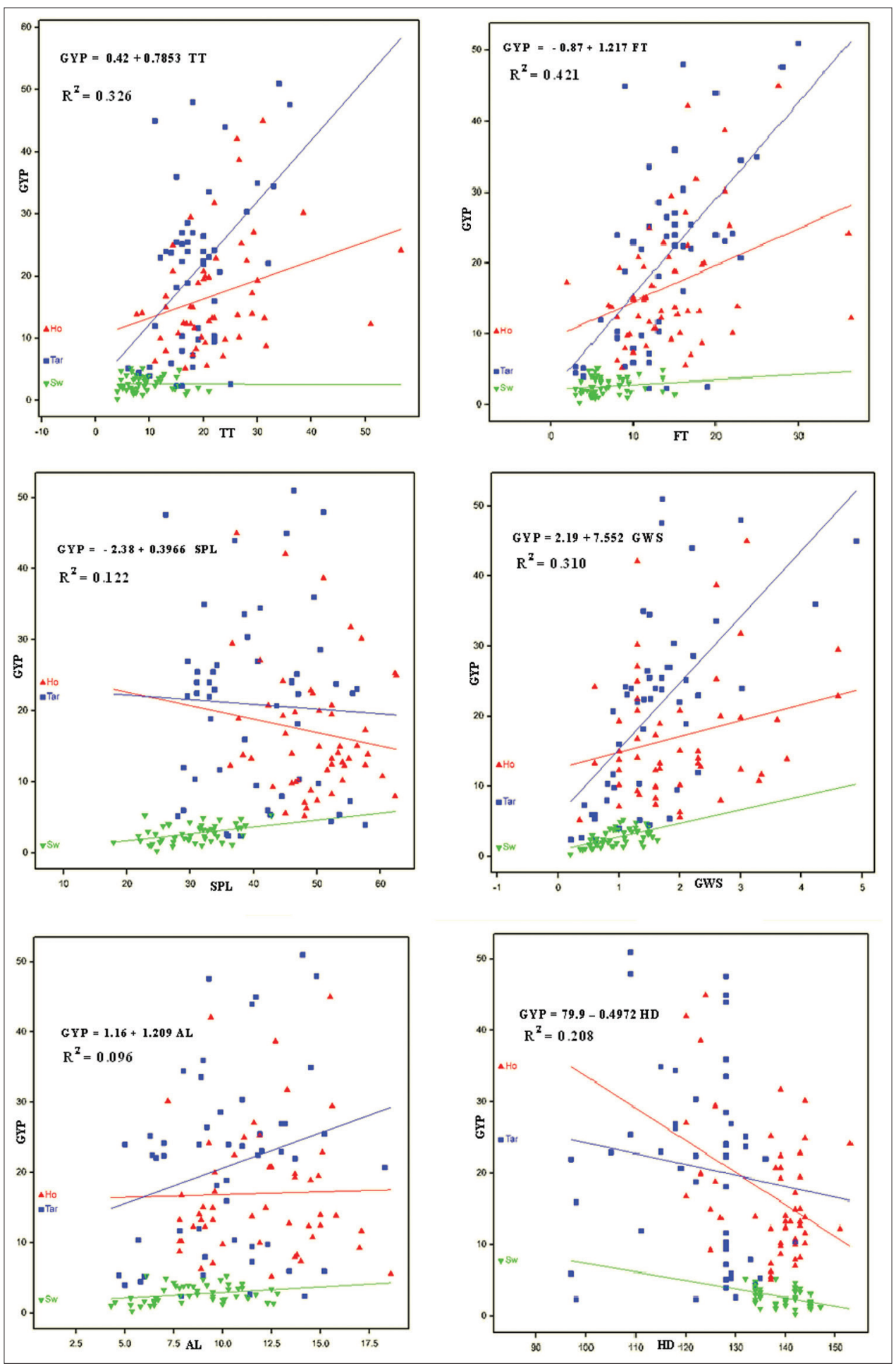

Figure 5: Loading plots of significant S.L.R between grain yield and predictors traits

high (63.7). Correlation between days to heading and grain yield was negative which means that late heading plants are accompanied with low yield and vice versa. Quantitative traits were mainly correlated positively with each other and with grain yield since they are affecting the final grain yield. These results were reported also by Marzougui et al. [12] who found that grain yield had significant and negative correlation with days to heading, while positive with spike peduncle length, and also positive between spike peduncle length and grains weight per spike, these were also approved $[13,14]$. Regarding Principle component analysis, the first four components represented about three quarter of variation which refer to the importance of the studied traits in providing wide variability to be explored, this agrees with the finding of Sisodia and Rai [15] who declared that the first principle components explain the main variability in various wheat genotypes. In addition, our results 
Table 9: Direct (underlined bold diagonal) and indirect effects of studied traits on grain yield per plant of wheat genotypes

\begin{tabular}{|c|c|c|c|c|c|c|c|c|c|c|c|c|}
\hline Trait & FD & HD & $\mathrm{PH}$ & $\mathrm{AL}$ & TT & FT & SL & SPL & GNS & GWS & TGW & $\mathrm{R}$ \\
\hline FD & 23038 & 33017 & 06796 & 0.00112 & 0.03080 & $L$ & 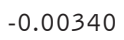 & & 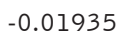 & 3 & 31 & \\
\hline D & & & & & & & & & & & & \\
\hline $\mathrm{PH}$ & & & & & 77 & & & & & & & 0.1 \\
\hline $\mathrm{L}$ & 451 & & & & & & & & & & & 0.3 \\
\hline $\mathrm{T}$ & & & & & & & & & & 28 & & 0.5 \\
\hline FT & & & & & 5 & & & & & 86 & & +90 \\
\hline$\$ \mathrm{~L}$ & 42 & 8 & & -0.8 & 0.00 & -0.0 & & & & & & -0.0605 \\
\hline SPL & 73 & -0.0 & -0.07 & -0.0 & 0.06192 & 0.0 & -0.0 & 7 & & 0.23409 & & 0.3499 \\
\hline NS & 3990 & -0.05197 & -0.03354 & -0.01917 & 0.02998 & 0.04 & -0.00 & 0.00 & & & -0.0 & 0.1495 \\
\hline GWS & 0.04488 & 0.03311 & -0.03747 & -0.025 & 0.02249 & 0.05752 & -0.00076 & 0.00135 & -0.05312 & 0.53401 & -0.0 & 0.5571 \\
\hline TGW & 0.08271 & -0.03062 & -0.04620 & -0.02850 & 0.01498 & 0.02060 & -0.00207 & 0.00145 & -0.01540 & 0.28364 & -0.03707 & 0.2435 \\
\hline
\end{tabular}

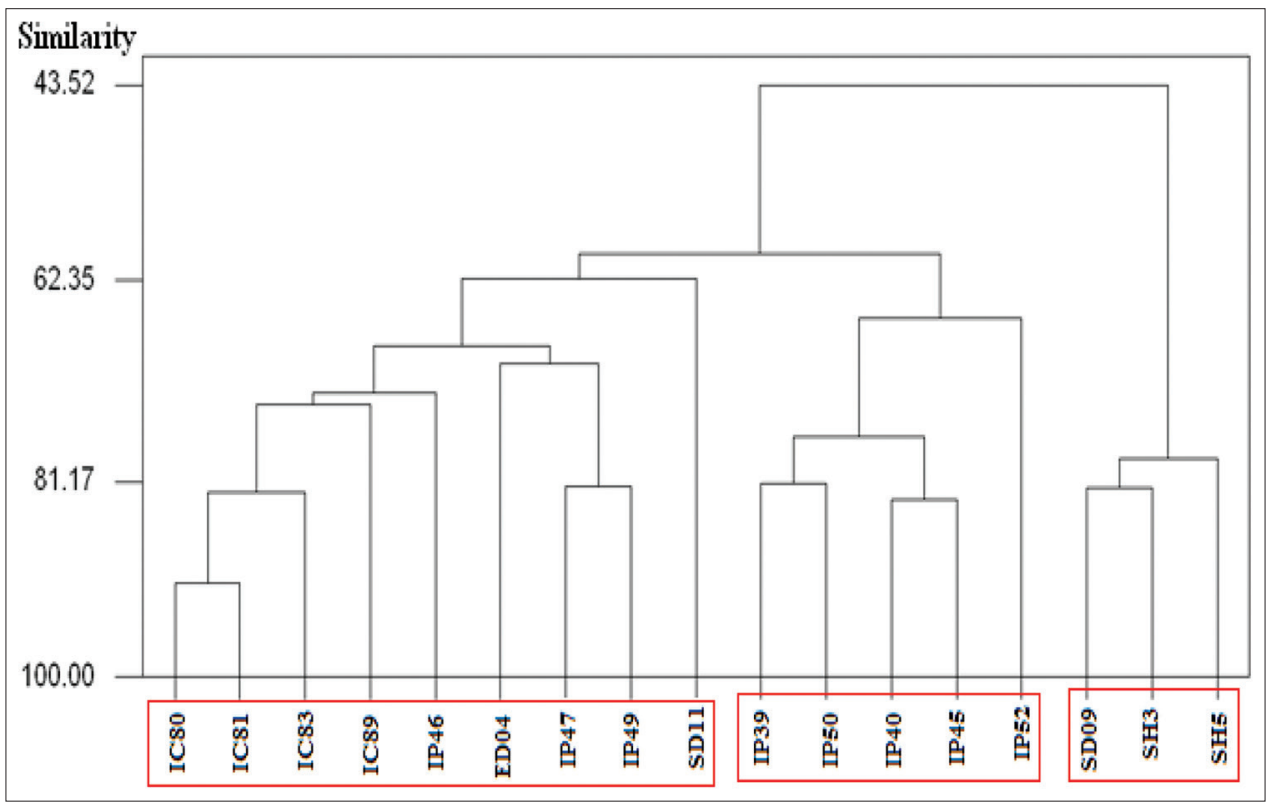

Figure 6: Dendrogram of studied wheat genotypes based on studied traits

are in agreement with results of Devesh et al. [1] who indicated that the $\mathrm{PCl}$ in wheat contained spike peduncle length and plant height, and PC3 contained tillers number per plant, and in general most of yield traits were located in the first three components. It was noticed that the Syrian originated genotype SD09 was the superior in grain yield per plant and this could be explained to its adaptability to local environments comparing with the exotic genotypes. Regression study between grain yield and days to heading revealed that the late heading genotypes will suffer from a grain yield reduction in rate of $20.8 \%$, while any raise in awn length, total tillers number per plant, fertile tillers number per plant, spike peduncle length and grains weight per plant will cause an increasing of grain yield in a rate of (9.6, 32.6, 42.1, 1.2 and 3.10) \% respectively, and these results sounds logic since these traits are related to yield as it is well-known, so these traits can be used as significant predictors for grain yield. Our findings are in agreement with many researchers' results [16-18]. Our results of cluster analysis concluded that most genotypes that obtained from the same origin gathered in the same cluster like the majority of Italian genotypes in the first cluster, as well as in the third cluster regarding the Syrian genotypes. Our results also insured that genotypes from the same species were clustered together like all Triticum polonicum genotypes in the second clusters. Wide variation was obvious between different cluster which make our results valuable for breeders to determine the method of choosing which genotypes to be used as parents for wheat improvement, This agrees with Mutwali et al. [19] who declared that related wheat genotypes were clustered together, and with [20] who reported that each cluster contains very close genotypes, and also with Jaiswal et al. [21]. According to path analysis results, both traits fertile tillers number per plant and grains weight per spike had positive strong direct effect on grain yield per plant and their correlation with grain yield were positive also, which means that both traits could be used effectively as selection indexes for grain yield, other scientists reported similar results $[22,23,24,25]$.

\section{CONCLUSIONS}

Valuable variation was confirmed according to our results between studied genotypes, caused by grain yield and most of the studied traits which be a sign of their importance. It was concluded also that the total and fertile tillers number per plant were the best predictors of the final grain yield per plant, and fertile tillers per plant with grains weight per spike could be used as selection indexes of wheat grain yield. Our results confirmed 
the necessity to evaluate different genotypes originated from many sources to get benefit of their variability and to emphasize on the Syrian genotype SD09 in wheat breeding program for yield improvement.

\section{CONFLICT OF INTEREST}

The authors declared that there is no conflict of interest.

\section{AUTHOR CONTRIBUTIONS}

Contribution were equal for all authors.

\section{REFERENCES}

1. Devesh P, Moitra PK, Shukla RS, Pandey S. Genetic diversity and principal component analyses for yield, yield components and quality traits of advanced lines of wheat. Journal of Pharmacognosy and Phytochemistry 2019; 8(3): 4834-4839.

2. Farshadfar $\mathrm{E}$, Romena $\mathrm{H}$, Safari $\mathrm{H}$. Evaluation of variability and genetic parameters in agro- physiological traits of wheat under rain-fed condition. International Journal of Agriculture and Crop Sciences. 2013: 5(9); 1015-1021.

3. Watson A, Hickey LT, Jack Christopher J, Rutkoski J, Poland J, Hayes BJ. Multivariate genomic selection and potential of rapid indirect selection with speed breeding in spring wheat. Crop Science, 2019: 59; 1945-1959.

4. Al-Otayk MS. Evaluation of agronomic traits and assessment of genetic variability in some popular wheat genotypes cultivated in Saudi Arabia. Australian Journal of Crop Science. 2019: 13(06); 847-856.

5. Shabir G, Naveed SA, Arif M. Estimation of phenotypic variability and mutual association of yield and its components in rice (Oryza sativa L.) germplasm using multivariate. analysis. Journal of Agricultural Research. 2013: 51(4); 361-378.

6. Poudel A, Thapa DP, Manoj S. Cluster analysis of wheat (Triticum aestivum L.) genotypes based upon response to terminal heat stress. International Journal of Applied Sciences and Biotechnology. 2017: 5(2); 188-193.

7. Sahu VK, Nair SK, Vishwakarma AK, Verulkar SB, Chandel G. Evaluations of F5 inbreed lines for estimation of genetic parameters, correlation and path analysis for yield and yield contributing traits in rice at two locations. International Journal of Agricultural and Statistics Sciences. 2017: 13(1); 243-251.

8. Abd El-Mohsen AA. Correlation and regression analysis in barley. Scientific Research and Review Journal. 2013: 1(3); 88-100.

9. Singh BK, Chudhary BD. Biometrical methods in quantitative genetic analysis. Kalyani Publishers. New Delhi. 1977.

10. Lenka D, Mishra B. Path coefficient analysis of yield in rice varieties. Indian Sciety of Agricultural Statistics. 1973: 143; 376-379.
11. Grzesiak S, Hordyńska N, Szczyrek P, Grzesiak MT, Noga A, SzechyńskaHebda M. Variation among wheat (Triticum aestivum L.) genotypes in response to the drought stress: I - selection approaches. Journal of Plant Interactions. 2019: 14(1); 30-44.

12. Marzougui S, Kharrat M, Younes MB. Marker-trait associations of yield related traits in bread wheat (Triticum aestivum L.) under a semi-arid climate. Czech Journal of Genetics and Plant Breeding. 2019: 55(4); 138-145.

13. Bhattarai RP, Ojha BR, Thapa DB, Kharel R, OjhaA, Sapkota M. Evaluation of elite spring wheat (Triticum aestivum L.) genotypes for yield and yield attributing traits under irrigated condition. International Journal of Applied Sciences and Biotechnology. 2017: 5(2); 194-202.

14. Khalili M, Naghavi MR. Interrelationships between characteristics of F4 wheat families under rain-fed conditions. International Journal of Agriculture and Biosciences. 2017: 6(1); 37- 41.

15. Anu, Sisodia BVS,. Rai VN. An application of principal component analysis for pre- harvest forecast model for wheat crop based on biometrical characters. International Research Journal of Agricultural Economics and Statistics. 2017: 8(1); 83-87.

16. Saleh MM, Moussa DS, Alkaraki NI, Abdurahman AL. Correlation, regression and path analysis among yield and yield traits in Triticum dicoccum. Journal of Experimental Sciences. 2018: 9; 24-27.

17. Ashraf A, Abd El-Mohsen, Abd El-Shafi MA. Regression and path analysis in Egyptian bread wheat, Journal of Agriculture-Food and Applied Sciences, 2014: 2(5); 139-148.

18. Olgun $M$, Aygün $C$. Evaluation of yield and yield components by different statistical methods in wheat (T. aestivum L.), Ph. D thesis, Faculty of Agriculture. Department of Field Crops. Eskisehir. Turkey, 2011.

19. Mutwali NIA, Mustafa Al, Gorafi YSA, Mohamed Ahmed IA. Effect of environment and genotypes on the physicochemical quality of the grains of newly developed wheat inbred lines, Food Science and Nutrition. 2016: 4(4); 508-520.

20. Jaiswal JP, Arya M, Kumar A, Swati R, Rawat RS. Assessing genetic diversity for yield and quality traits in indigenous bread wheat germplasm. Electronic Journal of Plant Breeding. 2010: 1(4); 370-378.

21. Awan SI, Ahmad SD, Ali MA, Ahmed MS, Rao A. Use of multivariate analysis in determining characteristics for grain yield selection in wheat. Sarhad Journal of Agriculture. 2015: 31(2); 139-150.

22. Fikre G, Alamerew S, Tadesse Z. Path Coefficient and Correlation Studies of Yield and Yield Associated Traits in Bread Wheat (Triticum Aestivum L.) Genotypes at Kulumsa Agricultural Research Center, South East Ethiopia. Food Science and Quality Management. 2015: 38; $14-23$.

23. Khan AA, Alam MA, Alam MK, Alam MJ, Sarker Zl. Genotypic and phenotypic correlation and path analysis in durum wheat (Triticum turgidum L. var. durum), Bangladesh Journal of Agriculture Research. 2013: 38(2); 219-225.

24. Sharma V, Pawar IS, Munjal R. Variability parameters, correlation and path coefficients for yield, its components and quality traits in bread wheat. National Journal of Plant Improvement. 2006: 8(2); 153-155.

25. Singh N, Singh T, Kumar N. Genetic variability and correlation analysis over different environments in bread wheat (T. aestivum L.). Plant Achieves. 2009: 9(2); 685-688. 